\title{
Assessment of Chlorella vulgaris, Scenedesmus obliquus, and Oocystis minuta for removal of sulfate, nitrate, and phosphate in wastewater
}

\author{
Sheriff Olalekan Ajala ${ }^{1,3} \cdot$ Matthew L. Alexander ${ }^{2}$
}

Received: 22 October 2019 / Accepted: 23 December 2019 / Published online: 3 January 2020

(c) The Author(s) 2020

\begin{abstract}
Application of wastewater for algal biomass production can not only lead to production of thousands of tons of biomass for subsequent biofuel production, but also can provide for significant removal of contaminants in wastewater. The aim of the present study is to evaluate the growth, contaminant removal, and biochemical component (lipid, carbohydrate, and protein) accumulation potential of Chlorella vulgaris, Scenedesmus obliquus, and Oocystis minuta cells in wastewater supplemented with different concentrations of sulfate, nitrate, and phosphate. The results show maximum biomass productivity of 33, 19, and $98 \mathrm{mg} \mathrm{dw} / \mathrm{L} / \mathrm{d}$ for C. vulgaris, S. obliquus, and O. minuta, respectively. Phosphate removal (more than 90\%) was highest in the culture with $O$. minuta; about $93 \%$ nitrate was removed by C. vulgaris, and the highest sulfate removal of $36 \%$ was observed in the culture with S. obliquus. The biochemical composition of the microalgae cells is in the ranges of 22-65\% carbohydrate, $19-38 \%$ protein, and 8-17\% lipid. This indicates that carbohydrate and protein are preferentially accumulated as compared to lipids under the growth conditions investigated for each of the microalgae strains.
\end{abstract}

Keywords Remediation $\cdot$ Lipids $\cdot$ Microalgae $\cdot$ Carbohydrate $\cdot$ Photosynthetic organism

$\begin{array}{ll}\text { Abbreviations } \\ \text { OD } & \text { Optical density } \\ \text { AFDW } & \text { Ash-free dry weight } \\ R^{2} & \text { Coefficient of determination } \\ P & \text { Biomass productivity } \\ t_{1}, t_{2} & \text { Culture duration, time } t_{1} \text { and } t_{2} \\ C_{1}, C_{2} & \text { Biomass concentrations at time, } t_{1} \text { and } t_{2} \\ A & \text { Mass of lipid in the extract } \\ B & \text { Mass of dried microalgae biomass } \\ \text { BSA } & \text { Bovine serum albumin }\end{array}$

Sheriff Olalekan Ajala

sheriffajalao@gmail.com

1 Sustainable Energy System Engineering, Texas A\&M University-Kingsville, Kingsville, USA

2 Chemical and Natural Gas Engineering, Texas A\&M University-Kingsville, Kingsville, USA

3 Frank H. Dotterweich College of Engineering, Texas A\&M University-Kingsville, 700 University Blvd MSC 188, Suite 301, Kingsville, TX 78363, USA

\section{Introduction}

The increasing demand for energy derived from fossil fuels can be offset by biofuel sources-first-generation, second-generation, and third-generation biofuel sources. The potential of third-generation biofuel feedstocks, which are microalgae-based, has received much attention owing to their advantages over the first- and second-generation feedstocks. Among such advantages are higher photosynthetic efficiency, greater utilization of $\mathrm{CO}_{2}$, and other growth nutrients such as nitrate and phosphate, it requires the use of non-arable land, and exhibits lower water demand compared to higher plant species [1]. Microalgae are also sources of valuable products like pigments, proteins, and antibiotics [2]. Additionally, microalgae can be grown in a wide range of environments like saline or brackish water, and municipal, agricultural, and industrial wastewaters [3]. Literature has revealed that wastewater sources contain enough of the primary growth nutrients, mostly nitrates and phosphate, that can sustain the growth of microalgae. For instance, a wastewater treatment plant located at Deer Island, Massachusetts, US has an approximate processing capacity of about 5773 megaliter/day and conservatively removes nitrates and phosphate by tertiary treatment to the tune of 288 metric ton/ day and 5.2 metric ton/day, respectively [4]. The application 
of such wastewater sources can lead to production of thousands of tons of microalgae biomass, which can be employed for biofuel production. Moreso, the ability of microalgae to utilize a myriad of contaminants ranging from organic carbon, inorganic (nitrates, phosphate, nitrites, sulfates, and ammonium), and metals present in wastewater sources is well reported [5]. The main motive of wastewater treatment is to reduce various contaminants that can adversely affect the aquatic life and thereby impact negatively on the environment [6]. Attempts to reduce these pollutants can be of economic advantages to the treatment plants and, at the same time, protect the ecosystems [7]. Chemical enrichment of growth medium can be reduced considerably when wastewater sources are utilized for algal cultivation [8]. And reduction of environmental problems associated with untreated wastewater discharges into streams and the decline in freshwater demand for microalgae cultivation are other added advantages. According to stoichiometry of photosynthesis equation (Eq. 1), about $0.75 \mathrm{~kg}$ of water is required for every $1 \mathrm{~kg}$ of biomass generated, which implies that for production of $1 \mathrm{~kg}$ of biodiesel, about $1.9 \mathrm{~kg}$ of freshwater is required based on the assumption of $40 \%$ lipid content of biomass [8]:

$$
\begin{aligned}
& \mathrm{CO}_{2}+0.93 \mathrm{H}_{2} \mathrm{O}+0.15 \mathrm{NO}_{3}^{-} \\
& \quad \longrightarrow \mathrm{CH}_{1.72} \mathrm{O}_{0.4} \mathrm{~N}_{0.15}+1.42 \mathrm{O}_{2}+0.15 \mathrm{H}^{-}
\end{aligned}
$$

Nevertheless, unreliability in the adequacy of growth nutrient in wastewater sources has led to some researchers suggesting the use of commercial nutrient media or addition of fertilizer to wastewater for algal cultivation [6]. Sulfated wastewater sources like power plants are one of those that the presence of growth nutrients is not guaranteed. The presence of sulfate in water above $250 \mathrm{mg} / \mathrm{L}$ can cause diarrhea, and dehydration in humans, and corrosion in pipelines systems, thus its removal becomes absolutely important [9]. Sulfate is the most common form of sulfur in wastewater. Although sulfate is inoffensive to the environment, the activities of sulfur reducing bacteria present in wastewater sources lead to production of sulfide, which has higher toxicity, corrosivity, and an offensive odor, and also is deleterious to human health [10]. Therefore, effective and efficient removal of sulfate from wastewater becomes important. Sulfate in wastewater can be removed by physical, chemical, and biological means. The high-energy requirements of physical methods like ion exchange and membrane filtration [10], and excessive chemical requirement for precipitation make these options less attractive. The biological removal by use of sulfur reducing bacteria has the demerit of releasing hydrogen sulfide to the atmosphere, which can be difficult to maintain anaerobic conditions as required for this method. The option of using microalgae for sulfate removal has been suggested and studied in a few cases $[10,11]$. Sulfated rich wastewater sources include wastewater from food and fermentation processes like yeast fermentation, where sulfuric acid or sulfate-rich chemicals are used as feedstock [12]. Other sources of sulfate-rich wastewater include power plants, where large volumes of water are used for cooling, ash transport, desulfurizing flue gas, boiler scrubbing, and demineralization for regeneration purposes [8]. The application of $\mathrm{CO}_{2}$ from flue gases (potential sulfate source) as the carbon source for microalgae cultivation has been proposed, and the search for microalgae strains tolerant to the oxides of sulfur and nitrogen among others in flue gases is important [2]. In view of the above, there is potential for huge volumes of sulfate-rich wastewater sources such as from a power plant and acid mine, to be employed in microalgae cultivation, if sulfate tolerant microalgae strains can be identified.

The focus of this work is to evaluate, in a batch culturing system, the growth of microalgae species in wastewater with different loadings of sulfate, nitrate, and phosphate. The lipid, protein, and carbohydrate contents of the microalgae biomass produced under the different concentrations of sulfate, nitrate, and phosphate in the wastewater were assessed. The sulfate, nitrate, and phosphate removal potential of the microalgae strains were evaluated, and the variation in $\mathrm{pH}$ and dissolved oxygen concentration of the batch cultivation were monitored.

\section{Materials and methods}

\section{Materials}

The chemicals (sodium nitrate, potassium phosphate, sodium hydroxide, hydrochloric acid, tetraoxosulfate(iv) acid, sodium bicarbonate, magnesium sulfate, phenol, Bradford reagent, methanol, and chloroform) used in this work are of analytical grade obtained from Fisher Scientific International, Inc. and VWR International Inc. Also, the bovine serum albumin (BSA) standard was purchased from Cepham Life Sciences, Inc. The microalgae strains (Chlorella vulgaris, Scenedesmus obliquus, and Oocystis minuta) were purchased from UTEX Culture Collection of Algae at The University of Texas at Austin. These microalgae strains were maintained (prior to use) in culture media purchased from UTEX.

\section{Wastewater source and characterization}

The microalgae culture medium used in this study was the secondary effluent of City of Kingsville wastewater treatment plant, supplemented with magnesium sulfate, sodium nitrate, and potassium phosphate. The wastewater sample was characterized for its level of sulfate, nitrate, and phosphate using ion chromatography (IC) method. The Dionex ICS-5004 + ion chromatograph system from Thermo Fisher 
Scientific, with $\mathrm{Na}_{2} \mathrm{CO}_{3}$ as an eluent, was employed. Also, the wastewater sample was supplemented with three different concentrations of sulfate, nitrate, and phosphate. Therefore, there are four different samples of the microalgae growth media prepared from the wastewater sample. The samples are tagged Case 1, Case 2, Case 3, and Case 4, where Case 1 is the secondary effluent without the addition of sulfate, nitrate, and phosphate, and it served as the control. The remaining cases have different levels of sulfate, nitrate, and phosphate concentrations as displayed in Table 1. The nitrate and phosphate added for the different cases were based on the artificial seawater medium composition obtained at UTEX website, which were varied, such that N/P ratios were within the optimum ratio recommended for microalgae growth. Sulfate additions were done, such that its concentrations were higher than reported ranges of values for municipal wastewater and closer to minimum ranges of values for some industrial sulfate-rich wastewaters such as acid mines wastewater. The $\mathrm{pH}$ of the wastewater sample and others were measured using an Orion star A211 pH meter. The conductivity of the media samples was measured using an Oakton ecoTestr conductivity meter (EC1 $0 \mu \mathrm{S}$ to $20 \mathrm{mS}$ ), and the dissolved oxygen concentration of the samples was measured using Hach Sension6 dissolved oxygen meter. The physiochemical properties of the wastewater with the different levels of sulfate, nitrate, and phosphate concentrations are depicted in Table 1.

\section{Microalgae cultivation}

Three species of microalgae-C. vulgaris, S. obliquus, and $O$. minuta - were cultured in the wastewater supplemented with different concentrations of sulfate, nitrate, and phosphate. Prior to their culture in wastewater, the species were cultured for 7 days in commercial microalgae growth media. The culture for each species was carried out in duplicate with the previous culture used as inoculum $(10 \% \mathrm{v} / \mathrm{v})$ for the culture that follows.
Four 1.5-L photobioreactors equipped with biological stirrer (Techne MCS-104L) were used for culturing the microalgae species for 14 days at room temperature. Sterilized air was continuously sparged at $0.02 \mathrm{vvm}$ with a $2 \% \mathrm{CO}_{2}$ sparging rate and light was supplied using daylight florescent tubes at $30,600 \mathrm{~lx}$ with $12: 12 \mathrm{~h}$ light-dark cycle. The culture was maintained at room temperature and the system was well mixed at stirring speed of $80 \mathrm{rpm}$. Microalgae growth and residual nutrient concentrations - sulfate, nitrate, and phosphate-were monitored every 2 days. Also, the residual sulfate, nitrate, and phosphate concentration were measured using the IC method. Dissolved oxygen concentration and the $\mathrm{pH}$ of the culture were measured at interval of 2 days. The microalgae culture was harvested after 14 days, and lipid, protein and carbohydrate concentrations of the biomass were evaluated.

\section{Analytical techniques}

\section{Microalgae growth and ash free dry weight measurement}

The microalgae growth was evaluated by measuring the optical density at $580 \mathrm{~nm}$ using a Unico S1200 Visible spectrophotometer. Meanwhile, the optical density, $\mathrm{OD}_{580}$, was initially correlated with ash free dry weight, AFDW $(\mathrm{mg} / \mathrm{L})$, and the correlation coefficients, and $R^{2}$ obtained for $C$. vulgaris, S. obliquus, and O. minuta were 0.999, 0.986, and 0.959, respectively:

$$
\begin{aligned}
& \mathrm{AFDW}_{\text {C.vulgaris }}=666.41 \times \mathrm{OD}_{580}-11.97 \\
& \mathrm{AFDW}_{\text {S.obliquus }}=874.54 \times \mathrm{OD}_{580}-49.752 \\
& \mathrm{AFDW}_{\text {O.minuta }}=890.89 \times \mathrm{OD}_{580}-73.655
\end{aligned}
$$

The microalgae biomass concentrations (ash free dry weight) were evaluated using gravimetry method. About $20 \mathrm{~mL}$ of microalgae broth was vacuum filtered using a
Table 1 Physiochemical properties of the wastewater and the different case studied

\begin{tabular}{lllll}
\hline Parameters/growth medium & \multicolumn{3}{l}{ Values } & \\
\cline { 2 - 5 } & Case 1 & \multicolumn{1}{l}{ Case 2 } & Case 3 & Case 4 \\
\hline $\mathrm{pH}$ & $8.50 \pm 0.22$ & $8.23 \pm 0.03$ & $7.94 \pm 0.06$ & $7.5 \pm 0.08$ \\
Dissolved oxygen (mg/L) & $6.97 \pm 0.50$ & $7.82 \pm 1.01$ & $7.73 \pm 0.40$ & $7.5 \pm 0.35$ \\
Color & Cloudy brown & - & - & - \\
Odor & Unpleasant & - & - & - \\
Sulfate (mg/L) & $475.34 \pm 22$ & $668.01 \pm 20$ & $792.99 \pm 49$ & $891.37 \pm 35$ \\
Nitrate $(\mathrm{mg} / \mathrm{L})$ & $123.63 \pm 16$ & $320.70 \pm 77$ & $377.56 \pm 50$ & $676.14 \pm 73$ \\
Phosphate $(\mathrm{mg} / \mathrm{L})$ & $14.67 \pm 0.8$ & $59.17 \pm 1.8$ & $104.70 \pm 8.1$ & $202.89 \pm 18$ \\
Electrical conductivity (mS/cm) & $3.01 \pm 0.03$ & - & - & - \\
Temperature $\left({ }^{\circ} \mathrm{C}\right)$ & $22.2 \pm 0.3$ & - & - & - \\
N/P ratio & $9: 1$ & $7: 1$ & $4: 1$ & $3: 1$ \\
\hline
\end{tabular}


pre-weighed membrane filter with pore size $0.2 \mu \mathrm{m}$ and diameter of $47 \mathrm{~mm}$. Then, it was rinsed with deionize water and the filtered biomass samples was dried at $80{ }^{\circ} \mathrm{C}$ in an oven overnight. Thereafter, it was cooled in a desiccator and weighed to calculate the dried weight in $20 \mathrm{~mL}$ of broth. This was performed in duplicate and the average was reported. Also, biomass productivity of the microalgae species was calculated based on Eq. 5:

$P=\frac{C_{2}-C_{1}}{t_{2}-t_{1}}$

where $P$ is biomass productivity (milligram dry weight per liter per day, [mg dw/L/d]), and $C_{2}$ and $C_{1}$ are the biomass concentrations $(\mathrm{mg} \mathrm{dw} / \mathrm{L})$ on dried basis at time $t_{2}$ and $t_{1}$, respectively.

\section{Estimation of residual sulfate, nitrate, and phosphate}

The concentrations of sulfate, nitrate, and phosphate in wastewater and culture broths were evaluated using ion chromatography (IC) method. All microalgae broth and wastewater samples were filtered using the polytetrafluoroethylene (PTFE) $0.20 \mu \mathrm{m}$ syringe filter to protect the column, the flow systems from damage and to obtain reliable and repeatable results. The carbonate-bicarbonate as an eluent was prepared as described in United States Environmental Protection Agency, US EPA document. In anion calibration standards, a blank, rinses, and about five combination anion calibration standards containing anions of interest (Dionex Seven Anion Standard II) were prepared according to EPA method [13]. The anion calibration standards were freshly prepared each time the analysis was conducted. Also, the filtrate samples of the microalgae broths were appropriately diluted prior to analysis. The analysis was done in replicates and the average values were reported. A detailed procedure of the IC method can be found in [13].

\section{Evaluation of lipid, carbohydrate, and protein}

The harvested microalgae biomass was dried in an oven at $80{ }^{\circ} \mathrm{C}$ to constant weight and pulverized using mortar and pestle. Lipid was extracted by the modified method of Bligh and Dyer [14]. About $1000 \mathrm{mg}$ of pulverized biomass was extracted in a $50 \mathrm{~mL}$ test tube with $19 \mathrm{~mL}$ of a mixture of chloroform, methanol and water in the ratio 0.26:0.53:0.21. The microalgae slurry was vortexed for about $10 \mathrm{~min}$ with subsequent addition of $10 \mathrm{~mL}$ mixture of chloroform and water (1:1). The mixture was further vortexed for $2 \mathrm{~min}$. The mixture was centrifuged at $2500 \mathrm{rpm}$ for $15 \mathrm{~min}$ to allow for separation into three layers. The bottom layer consisted of chloroform and extracted lipid, while the top methanol/water layer was thrown away. The middle layer which was residual biomass was repeatedly extracted as described earlier and the total lipid in the extracted phase was gravimetrically determined by allowing extracted mixture to evaporate in a pre-weighed aluminum dish in a fume hood. The total lipid was calculated as follows:

Total lipid $(\% \mathrm{w} / \mathrm{w})=\frac{A}{B} \times 100$

where $A$ is mass of lipid in the extract and $B$ is mass of dried microalgae biomass used in the extraction.

The phenol sulfuric acid method of Dubois et al. [15] was used in estimating the total sugar content of the microalgae biomass. The carbohydrate content of the microalgae was estimated using glucose as standard (Appendix B). A $1 \mathrm{~mL}$ of microalgae sample was centrifuged at $2500 \mathrm{rpm}$ for $10 \mathrm{~min}$ and the supernatant was discarded. The recovered microalgae cells were hydrolyzed with $1 \mathrm{~mL}$ of hydrochloric acid at $100{ }^{\circ} \mathrm{C}$ for about $2 \mathrm{~h}$. Thereafter, $200 \mu \mathrm{L}$ of the hydrolysate was added to an empty test tube and about 200 $\mu \mathrm{L}$ of aqueous phenol solution $(5 \% \mathrm{v} / \mathrm{v})$ was added. $1000 \mu \mathrm{L}$ of concentrated tetraoxosulfate (vi) acid was added and the mixture was allowed to sit for $10 \mathrm{~min}$ before it was vortexed for $30 \mathrm{~min}$. The optical density of the resulting solution was measured at $490 \mathrm{~nm}$ using a Unico S1200 Visible spectrophotometer. The total carbohydrate was estimated against a glucose standard curve.

The Bradford method [16] of protein analysis was employed for determination of protein content of the microalgae. A $1 \mathrm{~mL}$ microalgae sample was centrifuged at $2500 \mathrm{rpm}$ for $10 \mathrm{~min}$. The supernatant was removed, and the recovered microalgae cells were hydrolyzed with 1000 $\mu \mathrm{L}$ of sodium hydroxide $(1 \mathrm{~N})$ at $100^{\circ} \mathrm{C}$ for $2 \mathrm{~h}$. Afterward, about $100 \mu \mathrm{L}$ of the hydrolysate was place in a cuvette, followed by the addition of $1000 \mu \mathrm{L}$ of Bradford reagent. The obtained mixture was incubated at room temperature for about $10 \mathrm{~min}$, and then, the optical density was measured at $595 \mathrm{~nm}$. The result was then correlated with the standard curve prepared from bovine serum albumin (BSA) standard.

\section{Results and discussion}

\section{Microalgae growth and biomass productivity}

One of the bottlenecks to industrial scale production of microalgae-based biofuels is simultaneous enhancement of biomass production and biochemical components-lipid and carbohydrate production of different microalgae species. Optimization of microalgae biomass productivity is among the areas of interest in this field, and is currently been studied by adopting different techniques, such as manipulation of growth conditions [17]. Microalgae nutrient growth compositions are among growth parameters that significantly 
affect biomass productivity. In the current study, the effects of different loadings of sulfate, nitrate, and phosphate on microalgae growth and biomass productivity for three different species were evaluated.

Figures 1, 2 show the growth curves, biomass concentration and productivity of the microalgae strains under different sulfate, nitrate, and phosphate concentrationsCase 1, Case 2, Case 3, and Case 4. The results of corresponding nutrient consumption of the three different species of microalgae-C. vulgaris, S. obliquus, and O. minuta-were described in Sect. 3.2. In all the three species, maximum growth was observed in Case 3 after 14 days of culturing, with final biomass concentrations of 503, 686, and $1388 \mathrm{mg} \mathrm{dw} / \mathrm{L}$ for C. vulgaris, S. obliquus, and O. minuta, respectively (Figs. 1 and 2). Increased nitrate and phosphate concentrations in the growth media should have resulted in a corresponding increase in the growth rate of the microalgae, but the increase in the sulfate concentrations was probably responsible for the negative effect on microalgae growth. This is most evident in the growth of S. obliquus (Fig. 1b) in the wastewater supplemented growth medium Case 4, where the sulfate concentration was about $900 \mathrm{mg} / \mathrm{L}$.

Piligaev et al. [5] attributed lower microalgae (Chlorella sorokiniana, Parachlorella kessleri, Chlorella protothecoidies, S. obliquus, Desmodesmus sp., Parachlorella sp., Micractinium sp., and Chlorella sp.) growth in municipal wastewater, compared to synthetic growth medium, to lower
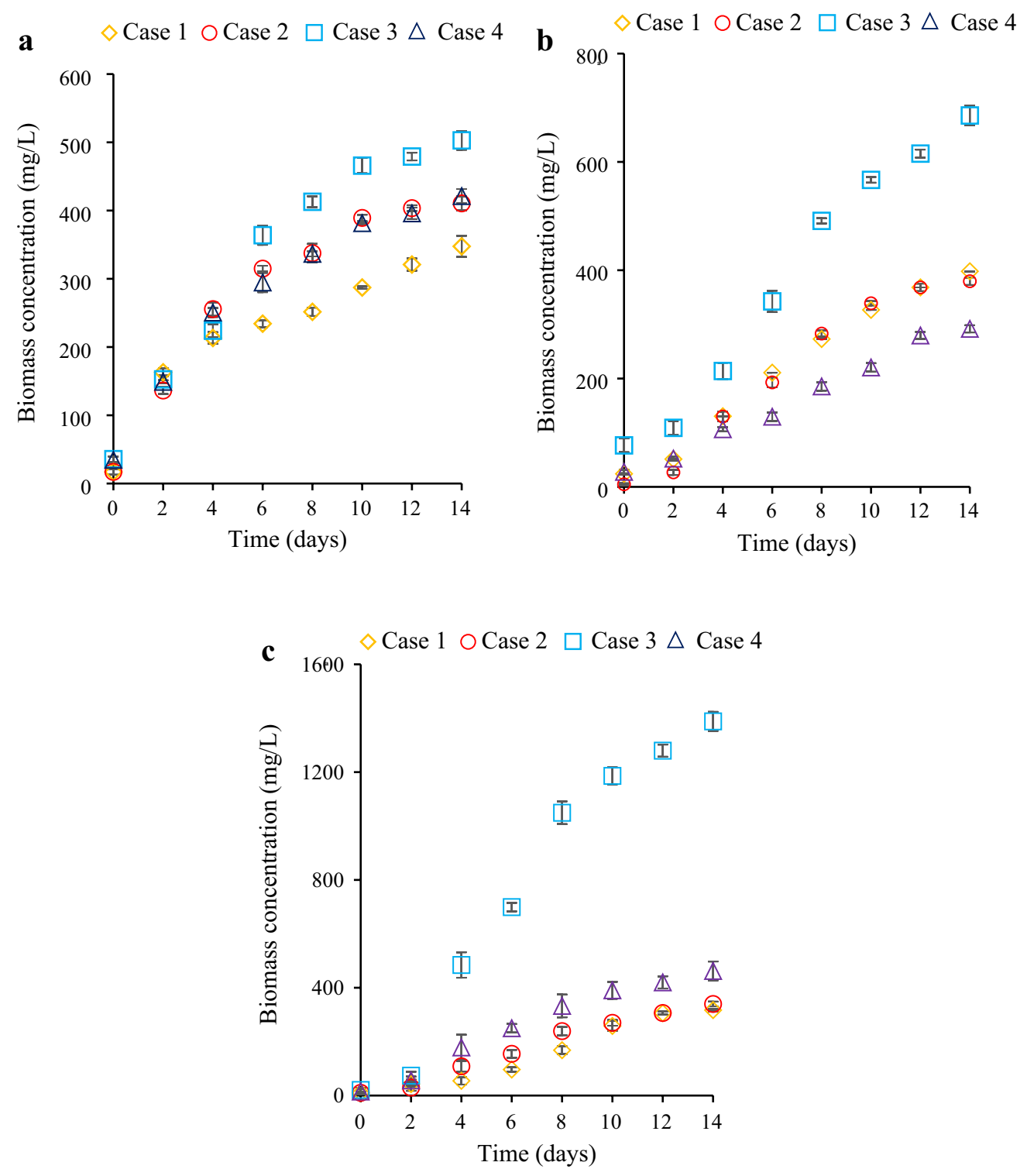

Fig. 1 Microalgae growth profiles in four supplemented wastewater samples: a C. vulgaris, b S. obliquus, and c O. minuta 

tion and productivity against wastewater sample cases: a $C$. vulgaris, b $S$. obliquus, and c $O$. minuta
Fig. 2 Biomass concentra-
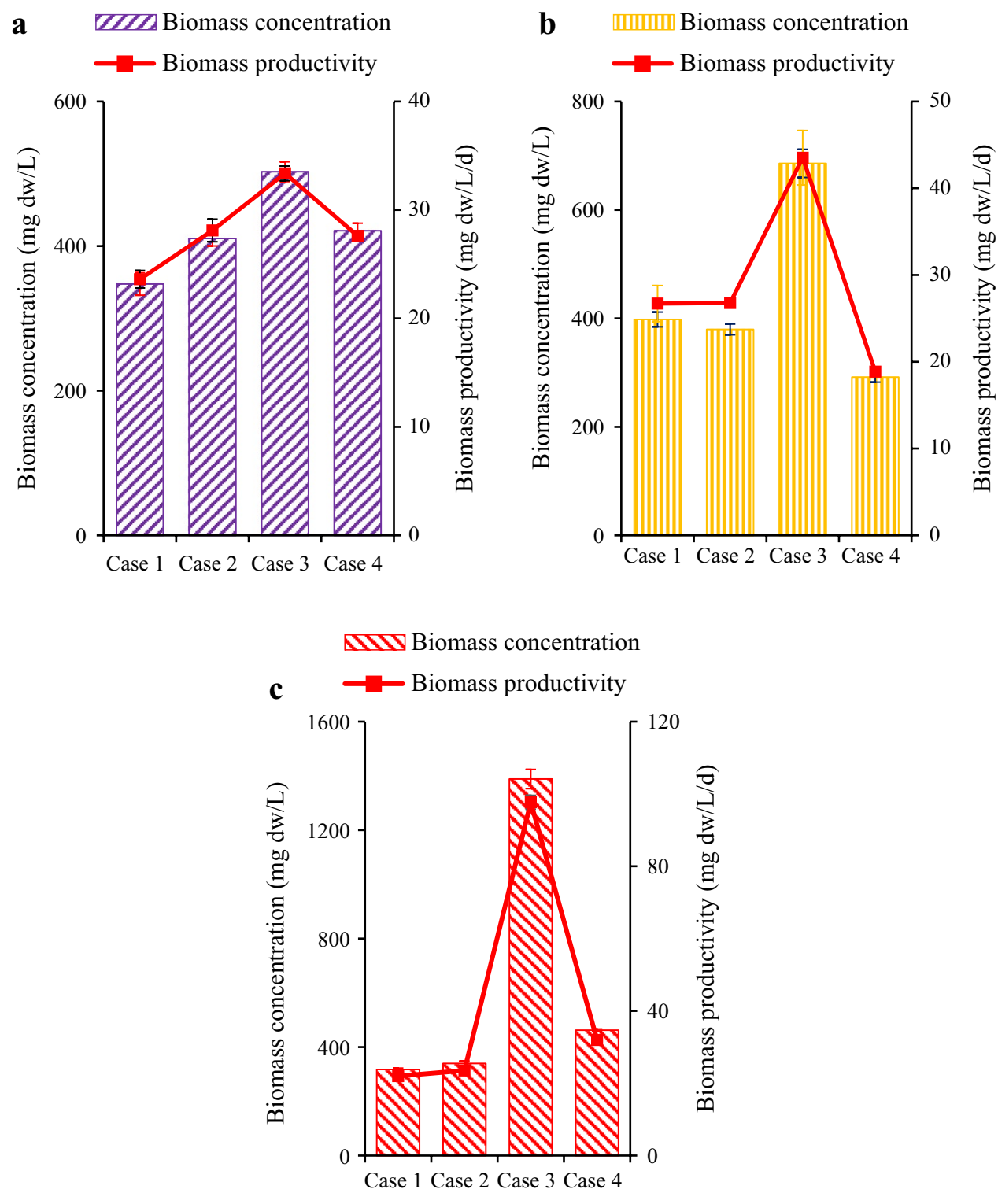

concentrations of nitrate, phosphate, and the presence of other toxic contaminants in the wastewater. Also, the highest concentrations of nitrate and phosphate in wastewater generated from sludge were reported by Wang et al. [3] to significantly enhance the growth of Chlorella sp. compared to other wastewater samples evaluated in the study. Mera et al. [18] reported sulfate concentration of $14.2 \mathrm{mg} / \mathrm{L}$ as the optimal growth sulfate requirement and concentration higher than $426.12 \mathrm{mg} / \mathrm{L}$ produced a toxic effect, not due to the presence of excess sulfate ions, but due to increased ionic strength of the medium. The importance of sulfate to microalgae growth was demonstrated by Lv et al. [19], in which the authors recorded a maximum biomass concentration of $325 \mathrm{mg} / \mathrm{L}$ in $271 \mathrm{mg} / \mathrm{L}$ sulfate in wastewater against $137 \mathrm{mg} / \mathrm{L}$ in wastewater without sulfate. The least biomass accumulation was generally observed (Fig. 1a and c) in the wastewater without sulfate, nitrate, and phosphate supplements. The microalgae species $O$. minuta has demonstrated its tolerant to high sulfate environment among the species cultivated (Fig. 1c). The growth potential of five species of microalgae (Chlorella sp., Chlamydomonas sp., Oocystis sp., Scenedesmus sp., and Fischerella sp.) in high sulfated power plant wastewater was assessed by Mohammadi et al. [11], and the authors observed that Chlorella sp. had the highest growth rate, unlike the present study.

Similar trends were also observed with biomass productivity obtained within 14 days of culturing (Fig. 2). In all four cases of wastewater evaluated for the microalgae species, biomass productivity was highest in the Case 3 . A comparison of microalgae grown in wastewater without and with supplements revealed that $41 \%$ higher biomass productivity was observed with $C$. vulgaris in Case 3, while about 19 and 
17\% were recorded for Cases 2 and 3 (Fig. 1a). In the case of S. obliquus, biomass productivity increased by $63 \%$ in wastewater sample Case 3, but declined to $30 \%$ with Case 4 , whereas there was no significant difference in what was observed in Case 2 (Fig. 2b). Moreso, O. minuta had the highest increase (78\%) in biomass productivity among the three species grown in wastewater and this was also recorded in Case 3 (Fig. 2c).

\section{Wastewater, supplemented wastewater compositions, and nutrient removal}

The physiochemical properties of wastewater and the wastewater supplemented with sulfate, nitrate, and phosphate are presented in Table 1 . The $\mathrm{pH}$ of wastewater was slightly alkaline (8.50), with a murky brown color and unpleasant smell. Addition of sulfate, nitrate, and phosphate reduces the $\mathrm{pH}$ of the wastewater to slightly neutral. The nitrate concentration $(124 \mathrm{mg} / \mathrm{L})$ for the secondary wastewater (Case 1) was significantly higher than the U.S. Environmental Protection Agency (EPA) recommended maximum contaminant level of $10 \mathrm{mg} / \mathrm{L}$ for drinking water [20]. Also, the sulfate concentration $(475 \mathrm{mg} / \mathrm{L})$ for the secondary effluent was more than the EPA recommended secondary maximum contaminant level of $250 \mathrm{mg} / \mathrm{L}$ [20]. The N/P ratio is within the suggested optimal values for microalgae growth except for Cases 3 and 4. Martin et al. [21] suggested that the optimal N/P ratio values are between 6.8 and 10 for microalgae growth. Figures 3, 4 show the changes in $\mathrm{pH}$ and dissolved oxygen (DO) of the culture broths during the period of cultivation. The changes in the $\mathrm{pH}$ of the culturing systems followed a similar pattern amongst the three species. The three microalgae species grew in the same $\mathrm{pH}$ range of 7.44-10.52. In all the species, the $\mathrm{pH}$ of the culturing broths increased from being slightly neutral to alkaline ( $\mathrm{pH}$ above 10). This trend is expected, because the $\mathrm{pH}$ of photosynthetic system is observed to increase due to hydroxide formation, resulting from release of oxygen molecules, a byproduct of photosynthesis [22]. Microalgae activities such as photosynthesis, along with alkalinity and ionic composition of the culture medium, coupled with the source of $\mathrm{CO}_{2}$ determine the $\mathrm{pH}$ of the
Fig. 3 Changes in $\mathrm{pH}$ of the culture systems: a $C$. vulgaris, $\mathbf{b}$ $S$. obliquus, and c $O$. minuta

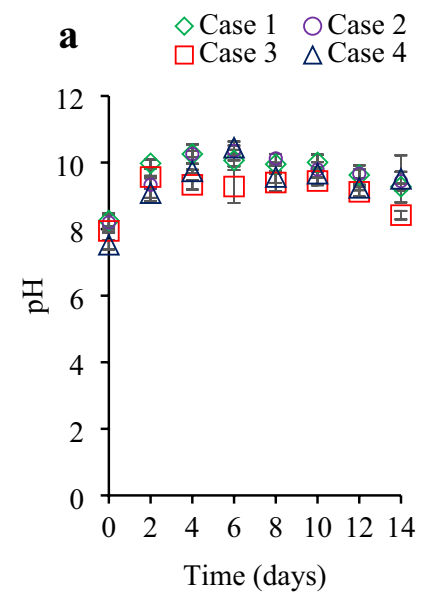

Fig. 4 Changes in dissolved oxygen concentrations of the culture systems: a C. vulgaris, b $S$. obliquus, and c O. minuta

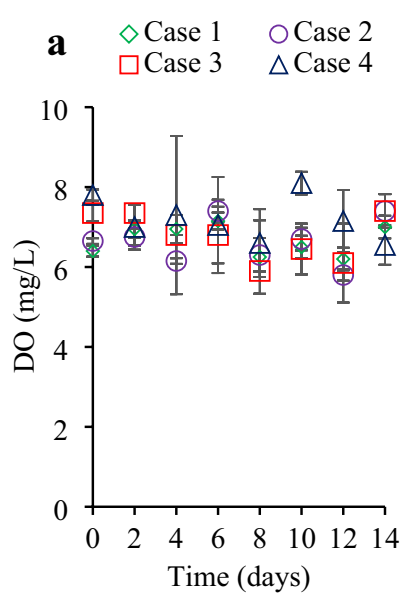

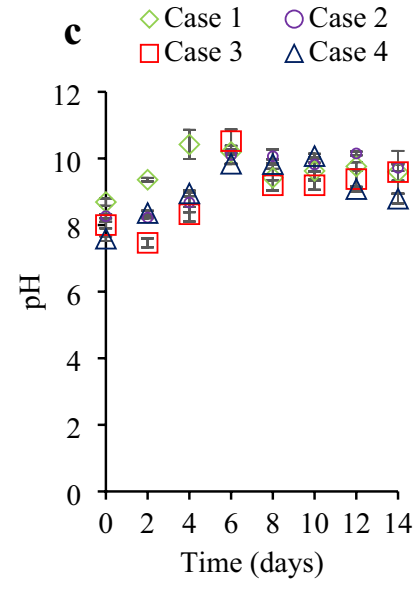

$\begin{array}{lll}\text { c } \quad \diamond \text { Case } 1 & \circ \text { Case } 2 \\ \square \text { Case } 3 & \triangle \text { Case } 4\end{array}$

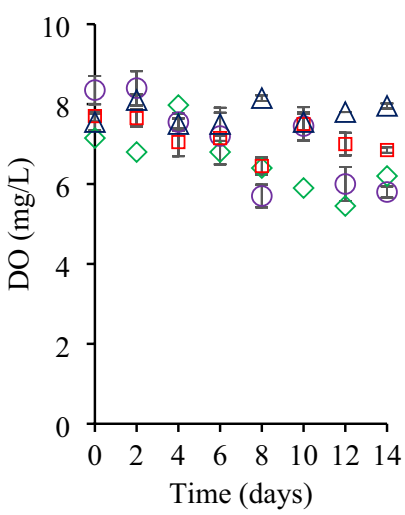


system [23]. The changes in DO of the culture systems also followed similar trends in all the cases and microalgae species cultured. Dissolved oxygen concentrations of the culturing media do not follow a regular pattern as it was observed to increase and decrease intermittently. The DO values ranged between 5.45 and $9.05 \mathrm{mg} / \mathrm{L}$. This is contrary to what it is expected whereby the DO of the culturing systems increases as the $\mathrm{pH}$ increases, due to formation of oxygen molecules, a byproduct of photosynthesis. Microalgae uptake of nutrients from the growth medium is largely dependent on the respective compositions in the medium [24]. The presence of nitrogen and phosphorus is essentially emphasized due to their support for microalgae growth. Lv et al. [19] stated that sulfur deficiency affects microalgae growth, contaminant removal, and self-flocculation of microalgae like Chlorococcum sp. Comparisons of sulfate, nitrate, and phosphate removal from this work and the ones reported in the literature using different wastewater sources and microalgae species are presented in Table 2. Microalgae nutrient removal in the present work is consistent with what has been previously published by other researchers as depicted in Table 2.

\section{Sulfate removal}

Sulfur removal from wastewater by microalgae, like other pollutants such as nitrate and phosphate, is a possibility owing to the assimilation of sulfur in synthesizing amino acids cysteine and methionine [18]. Figure 5 shows changes in the concentration of sulfate during the cultivation of the different microalgae species under different growth medium. It is observed that the sulfate concentration profiles are similar for all cases of wastewater and the microalgae species cultured. The sulfate removals ranged between 12 and $35 \%, 14$ and $36 \%$, and 6 and $27 \%$ for C. vulgaris, $S$. obliquus, and O. minuta, respectively (Fig. 5). These lower

Table 2 Nutrients' removal efficiencies of $C$. vulgaris, S. obliquus, and $O$. minuta compared to published works

\begin{tabular}{|c|c|c|c|c|c|c|c|}
\hline \multirow[t]{2}{*}{ Media type } & \multirow[t]{2}{*}{ Microalgae type } & \multicolumn{3}{|c|}{ Nutrient removal efficiency $(\%)$} & \multirow{2}{*}{$\begin{array}{l}\text { Biomass } \\
\text { conc. } \\
(\mathrm{g} / \mathrm{l})\end{array}$} & \multirow{2}{*}{$\begin{array}{l}\text { Culture } \\
\text { duration } \\
\text { (day) }\end{array}$} & \multirow[t]{2}{*}{ References } \\
\hline & & $\mathrm{N}$ & $\mathrm{P}$ & $\mathrm{S}$ & & & \\
\hline Municipal wastewater & Scenedesmus obliquus & $\begin{array}{l}\mathrm{NH}_{4}^{+:}: 81.9 \\
\mathrm{NO}_{3}^{-}: 100\end{array}$ & $\mathrm{PO}_{4}{ }^{3-}: 94$ & - & 0.88 & 16 & {$[6]$} \\
\hline Secondary wastewater & Chlorella vulgaris & $\mathrm{TN}: 83$ & TP:100 & - & 1.16 & 13 & {$[26]$} \\
\hline Primary wastewater & Chlorella vulgaris & $\mathrm{TN}: 80$ & TP: 100 & & 1.6 & 13 & {$[26]$} \\
\hline Municipal wastewater & $\begin{array}{l}\text { Auxenochlorella protothe- } \\
\text { coides }\end{array}$ & TN:59.70 & TP:81.52 & - & $>1.10$ & 6 & {$[26]$} \\
\hline Aquaculture wastewater & Chlorella sorokiniana & $\begin{array}{l}\mathrm{NH}_{4}^{+}: 98.2 \\
\mathrm{NO}_{3}^{-}: 75.8 ; \mathrm{NO}_{2}^{-}: 81.8\end{array}$ & $\mathrm{PO}_{4}^{3-}: 100$ & - & 1.51 & 14 & {$[28]$} \\
\hline Sewage wastewater & $\begin{array}{l}\text { Chlorella vulgaris }^{\mathrm{a}} \\
\text { Chlorella vulgaris }^{\mathrm{b}}\end{array}$ & $\begin{array}{l}\mathrm{NO}_{3}^{-}: 91 \\
\mathrm{NO}_{3}^{-}: 95\end{array}$ & $\begin{array}{l}\mathrm{PO}_{4}{ }^{3-}: 55 \\
\mathrm{PO}_{4}{ }^{3-}: 49\end{array}$ & $\begin{array}{l}\mathrm{SO}_{4}{ }^{2-}: 26 \\
\mathrm{SO}_{4}{ }^{2-}: 49\end{array}$ & & $\begin{array}{l}15 \\
15\end{array}$ & $\begin{array}{l}{[30]} \\
{[30]}\end{array}$ \\
\hline Municipal wastewater ${ }^{\mathrm{c}}$ & Chlorella vulgaris & $\mathrm{NO}_{3}^{-}: 68$ & $\mathrm{PO}_{4}{ }^{3-}: 94$ & $\mathrm{SO}_{4}{ }^{2-}: 34$ & 0.41 & 14 & This study \\
\hline Municipal wastewater ${ }^{c}$ & Scenedesmus obliquus & $\mathrm{NO}_{3}^{-}: 52$ & $\mathrm{PO}_{4}^{3-}: 83$ & $\mathrm{SO}_{4}^{2-}: 36$ & 0.38 & 14 & This study \\
\hline Municipal wastewater ${ }^{\mathrm{c}}$ & Oocystis minuta & $\mathrm{NO}_{3}^{-}: 56$ & $\mathrm{PO}_{4}{ }^{3-}: 95$ & $\mathrm{SO}_{4}{ }^{2-}: 27$ & 0.34 & 14 & This study \\
\hline Municipal wastewater ${ }^{\mathrm{d}}$ & Chlorella vulgaris & $\mathrm{NO}_{3}^{-}: 41$ & $\mathrm{PO}_{4}{ }^{3-}: 84$ & $\mathrm{SO}_{4}{ }^{2-}: 18$ & 0.50 & 14 & This study \\
\hline Municipal wastewater ${ }^{\mathrm{d}}$ & Scenedesmus obliquus & $\mathrm{NO}_{3}^{-}: 59$ & $\mathrm{PO}_{4}{ }^{3-}: 90$ & $\mathrm{SO}_{4}{ }^{2-}: 31$ & 0.69 & 14 & This study \\
\hline Municipal wastewater ${ }^{\mathrm{d}}$ & Oocystis minuta & $\mathrm{NO}_{3}^{-}: 79$ & $\mathrm{PO}_{4}{ }^{3-}: 90$ & $\mathrm{SO}_{4}{ }^{2-}: 27$ & 1.4 & 14 & This study \\
\hline Aquaculture wastewater & Chlorella sorokiniana & $\begin{array}{l}\mathrm{NH}_{4}^{+}: 75.6 \\
\mathrm{NO}_{3}^{-}: 84.5 \mathrm{NO}_{2}^{-}: 96.4\end{array}$ & $\mathrm{PO}_{4}^{3-}: 74$ & - & 2.47 & & {$[31]$} \\
\hline Power plant wastewater & Chlamydomonas sp. & - & - & $\mathrm{SO}_{4}{ }^{2-}: 26$ & 0.42 & 21 & [11] \\
\hline Power plant wastewater & Fischerella sp. & - & - & $\mathrm{SO}_{4}{ }^{2-}: 23$ & 0.28 & 21 & [11] \\
\hline Power plant wastewater & Scenedesmus sp. & - & - & $\mathrm{SO}_{4}{ }^{2-}: 25$ & 0.55 & 21 & [11] \\
\hline Power plant wastewater & Oocystis sp. & - & - & $\mathrm{SO}_{4}{ }^{2-}: 32$ & 0.53 & 21 & [11] \\
\hline $\begin{array}{l}\text { Synthetic acid mine waste- } \\
\text { water }\end{array}$ & Algal polyculture ${ }^{\mathrm{e}}$ & - & - & $\mathrm{SO}_{4}{ }^{2-}: 25$ & & 28 & [10] \\
\hline $\begin{array}{l}\text { Synthetic acid mine waste- } \\
\text { water }\end{array}$ & Algal polyculture ${ }^{f}$ & - & - & $\mathrm{SO}_{4}{ }^{2-}: 45$ & & 28 & {$[10]$} \\
\hline Power plant wastewater & Dictyosphaerium sp. & - & - & $\mathrm{SO}_{4}^{2-}: 37$ & & 21 & {$[25]$} \\
\hline
\end{tabular}

Chlorella vulgaris $^{\mathrm{a}}$ Continuous, Chlorella vulgaris ${ }^{\mathrm{b}}$ batch, municipal wastewater ${ }^{\mathrm{c}}$ case 2 , municipal wastewater ${ }^{\mathrm{d}}$ case 3 , algal polyculture ${ }^{\mathrm{e}}$, bubble column reactor, algal polyculture ${ }^{\mathrm{f}}$ revolving algal biofilm reactor 
Fig. 5 The changes in the sulfate concentration during the period of culture: a $C$. vulgaris, b $S$. obliquus, and c $O$. minuta
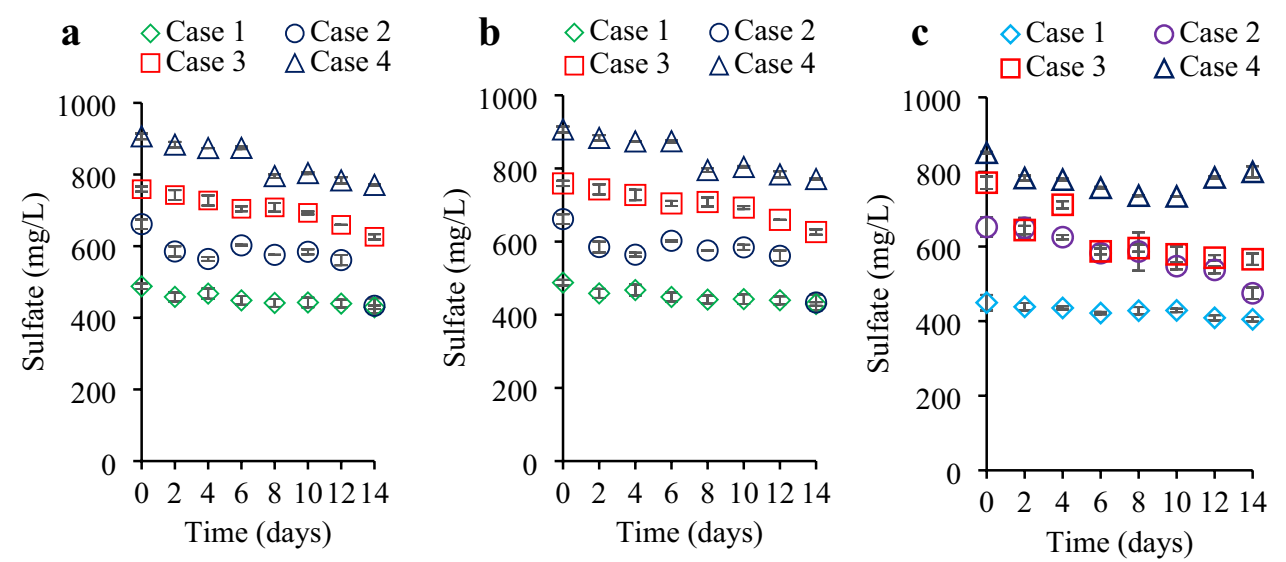

\section{Nitrate removal}

essential nutrients like nitrate and phosphate, are attributed to competition among these chemical species [11]. The observed sulfate removal by microalgae within 14 days of cultivation in the present work is comparable with the other published works (Table 2). The highest sulfate removals of $36 \%, 34 \%$, and $27 \%$ were observed in cultures of $S$. obliquus, C. vulgaris, and O. minuta, respectively, when the species were cultured in supplemented wastewater Case 2. A study by Mohammadi et al. [11] showed that Dictyosphaerium sp. was able to remove about $37 \%$ sulfate in power plant wastewater. A similar work by Mohammadi et al. [11] revealed that $O$. minuta had the highest sulfate removal of $32 \%$ among five microalgae species cultured in power plant wastewater. The report by Kumar et al. [26] showed highest sulfate removal of $49 \%$ and $26 \%$ when $C$. vulgaris was cultured under batch and continuous mode, respectively. Algal polyculture with highest proportion of C. vulgaris was employed by Zhou et al. [11] for removing sulfate in acid mine drainage. The authors reported $25 \%$ and $45 \%$ sulfate removal within 28 days of cultivation using bubble column and revolving algal biofilm reactors, respectively.

Fig. 6 The nitrate concentration profile during the culturing period: a $C$. vulgaris, $\mathbf{b} S$. obliquus, and c $O$. minuta

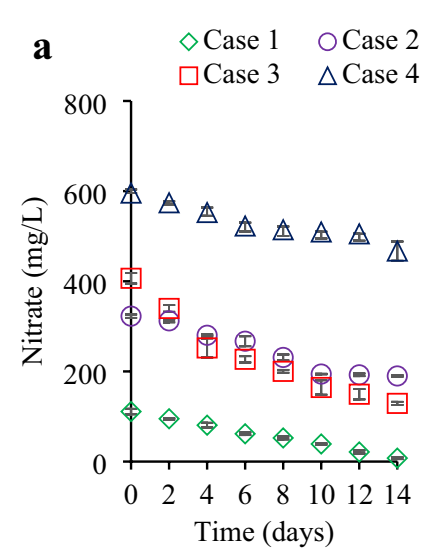

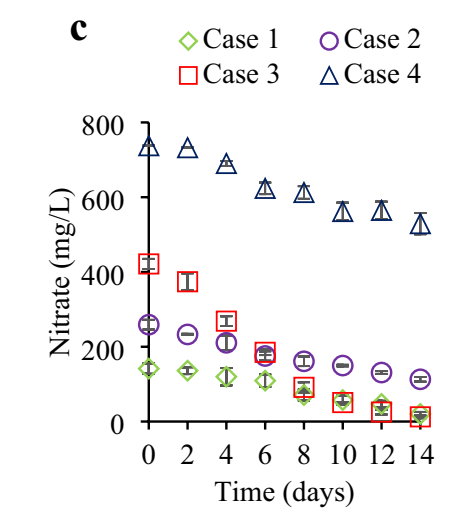

Nitrogen is a component of amino acids, which are building blocks of proteins, and thus, nitrate and other inorganic nitrogen sources are assimilated into amino acid via different pathways [32]. Microalgae commonly uptake inorganic nitrogen species such as nitrate, nitrite, and ammonia present in the growth medium [1]. Figure 6 reveals the decline in concentration of nitrogen-nitrate $\left(\mathrm{N}-\mathrm{NO}_{3}{ }^{-}\right)$in the culture broth during the period of cultivation. Although a similar trend was observed in the nitrate concentration-time curve for all species, the highest and lowest nitrate reductions of about $93 \%$ and $23 \%$ after 14 days of cultivation were observed in $C$. vulgaris grown in culture medium Case 1 and 4 , respectively (Fig. 6a). The nitrate removal by $O$. minuta were about $86 \%, 56 \%, 79 \%$, and $28 \%$ when cultured in the growth medium Case 1, Case 2, Case 3, and Case 4, respectively. The S. obliquus has the lowest performance in nitrate removal from the culturing medium. And the maximum and the minimum nitrate removal of $69 \%$ and $28 \%$ were recorded when cultivated in growth medium Cases 1 and 4, respectively. The results reported in the current study were analogous to what other authors observed as depicted

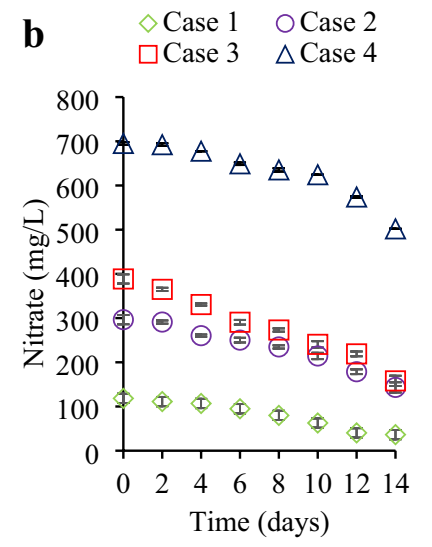


in Table 2. Ahmad et al. [6] reported 100\% nitrate reduction when $S$. obliquus was cultured in municipal wastewater. The total nitrate removal of about $60 \%$ was reported by [28] during growth of $A$. protothecoides in municipal wastewater after 6 days. Guldhe et al. [31] reported $76 \%$ of nitrate removal with $C$. sorokiniana in aquaculture wastewater. Microalgae assimilates inorganic nitrogen in any of the three available forms-nitrate, nitrite, and ammonium by translocating across the plasma membrane of the cells and subsequently reducing the oxidized nitrogen [33]. The results show that the evaluated microalgae strains can effectively remove nitrate and can be potentially employed in a treatment process. The biomass yield based on nitrate for the microalgae ranged $1.37-4.56 \mathrm{mg} \mathrm{dw} / \mathrm{L} / \mathrm{mg} / \mathrm{L}$ for $S$. obliquus, $1.68-3.20 \mathrm{mg} \mathrm{dw} / \mathrm{L} / \mathrm{mg} / \mathrm{L}$ for $C$. vulgaris, and $2.15-4.11 \mathrm{mg}$ $\mathrm{dw} / \mathrm{L} / \mathrm{mg} / \mathrm{L}$ for $O$. minuta.

\section{Phosphate removal}

Phosphorous is an essential constituent of algal cells because of its role in producing adenosine triphosphate and reducing nicotinamide adenine dinucleotide phosphate $\left(\mathrm{NADP}^{+}\right)$that drives cellular energy processes in living cells [34]. Thus, the microalgae demand for phosphorous is met by consumption of phosphate in growth medium. Figure 7 shows the variation of phosphate concentration during the microalgae cultures. Initially, the phosphate uptake was very rapid in the first 6-8 days of culturing, depending on the strains and wastewater case employed. This corresponds to the exponential growth phase of the microalgae cells. The uptake of phosphorus-phosphate $\left(\mathrm{P}-\mathrm{PO}_{4}{ }^{3-}\right)$ by all the microalgae strains is comparable in all cases, with values ranging from about $67-100 \%$ of the initial concentrations (Fig. 7). The $O$. minuta has indicated a better phosphate consumption in all the cases with more than $90 \%$ of initial value and almost $100 \%$ in culture media Case 1 (wastewater without supplements). The biomass yield based on phosphate for the microalgae ranged $1.80-29.09 \mathrm{mg} \mathrm{dw} / \mathrm{L} / \mathrm{mg} / \mathrm{L}$ for $S$. obliquus, $2.36-26.65 \mathrm{mg} \mathrm{dw} / \mathrm{L} / \mathrm{mg} / \mathrm{L}$ for $C$. vulgaris, and 2.73-19.86 mg dw/L/mg/L for O. minuta. The observed values for phosphate removal efficiencies in the present study are comparable to what is reported in the literature, as depicted in Table 2. Ansari et al. [29] reported 100\% phosphate removal when $C$. sorokiniana was cultivated in aquaculture wastewater for 14 days. The phosphate consumption of about $55 \%$ of initial concentration was observed by [26] after 15 days of culturing $C$. vulgaris in sewage wastewater. The findings of Ahmad et al. [6] showed that S. obliquus was able to remove $94 \%$ phosphate from municipal wastewater. The inorganic nutrient removal from growth media is reported not to be limited only by microalgae cell uptake, but also by volatilization (ammonium) and precipitation (phosphate) due to increase in $\mathrm{pH}$, temperature, and dissolved oxygen as the case may be [31].

\section{Nutrient uptake mechanism}

The elemental component analysis of harvested microalgae biomass, residual nutrient analysis of culture broth (Table 3), and subsequent elemental mass balance is one of the commonly used methods to identify nutrient removal mechanism. Aside from nutrient assimilation by microalgae, other nutrient removal mechanisms include volatilization and precipitation of nutrients; these are commonly observed at high $\mathrm{pH}$ values in the range of 9-11 [34, 35]. In the present study, the nitrogen, phosphorous, and sulfur content within the cultured microalgae were not measured. Nonetheless, it is conceivable to state that phosphates were predominantly removed by active uptake, instead of precipitated as insoluble phosphorous salt at the high $\mathrm{pH}$ ranges observed in the cultures. This is because atom-to-atom N:P ratios evaluated using actual nitrogen uptake (as protein component) and the mean amount of phosphorus removed from the cultures were less than $6: 1$ in all cases investigated are within classical Redfield ratio of 16: 1. Similarly, nitrates were actively uptake by microalgae. The mechanism of sulfate removal
Fig. 7 The phosphate concentration profile during the culturing period: a $C$. vulgaris, $\mathbf{b} S$. obliquus, and c $O$. minuta

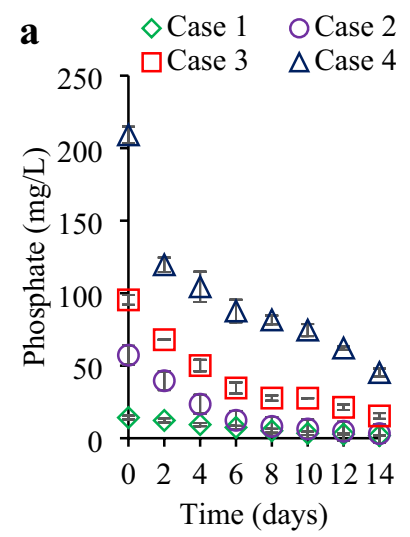

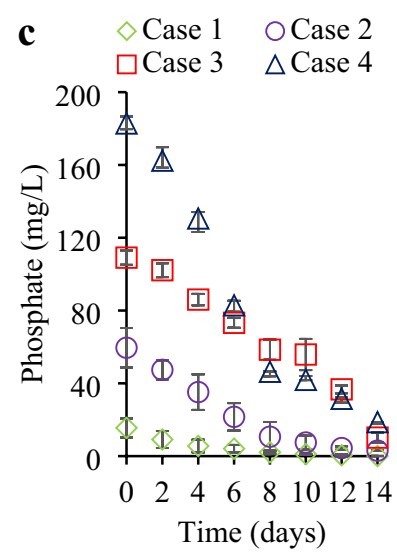


Table 3 Initial and final mean concentrations $(\mathrm{mg} / \mathrm{L})$ of nitrate, phosphate, and sulfate in batch cultures of microalgae grown in wastewater cases, \% removal, and standard deviations are in brackets

\begin{tabular}{|c|c|c|c|c|c|c|c|c|c|}
\hline & \multicolumn{3}{|l|}{ C. vulgaris } & \multicolumn{3}{|l|}{ S. obliquus } & \multicolumn{3}{|l|}{ O. minuta } \\
\hline & $\mathrm{N}-\mathrm{NO}_{3}{ }^{-}$ & $\mathrm{P}-\mathrm{PO}_{4}{ }^{3-}$ & $\mathrm{S}-\mathrm{SO}_{4}{ }^{2-}$ & $\mathrm{N}-\mathrm{NO}_{3}{ }^{-}$ & $\mathrm{P}-\mathrm{PO}_{4}{ }^{3-}$ & $\mathrm{S}-\mathrm{SO}_{4}{ }^{2-}$ & $\mathrm{N}-\mathrm{NO}_{3}^{-}$ & $\mathrm{P}-\mathrm{PO}_{4}{ }^{3-}$ & $\mathrm{S}-\mathrm{SO}_{4}{ }^{2-}$ \\
\hline Case 1 & & & & Case 1 & & & Case 1 & & \\
\hline Initial & $111.0(6.0)$ & $14.2(1.3)$ & $487.9(7.5)$ & $118.3(2.9)$ & $14.3(1.8)$ & $488.6(3.1)$ & $141.6(13.7)$ & $15.5(5.3)$ & $449.6(20.7)$ \\
\hline Final & $7.7(2.2)$ & $1.8(0.3)$ & $429.5(5.1)$ & $36.3(1.8)$ & $1.4(0.3)$ & $416.1(20.0)$ & $20.3(5.6)$ & $0.1(0.1)$ & $404.8(6.2)$ \\
\hline \% Removal & $93.1 \%$ & $87.3 \%$ & $12.0 \%$ & $69.3 \%$ & $90.1 \%$ & $14.8 \%$ & $85.7 \%$ & $99.6 \%$ & $10.0 \%$ \\
\hline Case 2 & & & & Case 2 & & & Case 2 & & \\
\hline Initial & $322.6(3.9)$ & $57.3(14.6)$ & $661.5(13.5)$ & $296.4(3.3)$ & $60.7(4.5)$ & $690.2(1.9)$ & $259.1(13.0)$ & $59.6(10.8)$ & $652.4(26.8)$ \\
\hline Final & $190.0(1.9)$ & $3.2(1.1)$ & $433.5(21.2)$ & $143.2(3.2)$ & $10.0(0.2)$ & $443.6(5.3)$ & $113.0(6.3)$ & $3.0(0.2)$ & $474.7(15.4)$ \\
\hline$\%$ Removal & $41.1 \%$ & $94.5 \%$ & $34.5 \%$ & $51.7 \%$ & $83.5 \%$ & $35.7 \%$ & $56.4 \%$ & $94.9 \%$ & $27.2 \%$ \\
\hline Case 3 & & & & Case 3 & & & Case 3 & & \\
\hline Initial & $406.6(11.7)$ & $95.39(3.4)$ & $759.0(7.2)$ & $388.5(10.4)$ & $109.7(3.3)$ & 848.7 (6.4) & $421.5(13.6)$ & $109.1(4.0)$ & $771.2(16.9)$ \\
\hline Final & $129.1(3.4)$ & $15.4(2.0)$ & $626.1(7.4)$ & $158.0(11.6)$ & $11.4(1.4)$ & $583.3(0.6)$ & $88.4(3.8)$ & $10.2(2.8)$ & $565.9(15.2)$ \\
\hline$\%$ Removal & $68.2 \%$ & $83.9 \%$ & $17.5 \%$ & $59.3 \%$ & $89.6 \%$ & $31.3 \%$ & $79.0 \%$ & $90.7 \%$ & $26.6 \%$ \\
\hline Case 4 & & & & Case 4 & & & Case 4 & & \\
\hline Initial & $595.7(8.0)$ & $209.2(5.7)$ & $906.6(8.0)$ & $695.1(3.0)$ & $216.7(4.7)$ & $916.0(4.5)$ & $737.7(9.1)$ & $182.8(3.1)$ & $851.5(2.4)$ \\
\hline Final & $467.0(21.2)$ & $45.3(2.8)$ & $771.1(1.7)$ & $501.8(0.5)$ & $69.9(0.1)$ & $784.6(4.6)$ & $529.2(1.2)$ & $18.7(0.8)$ & $800.2(15.2)$ \\
\hline$\%$ Removal & $21.6 \%$ & $78.4 \%$ & $15.0 \%$ & $27.8 \%$ & $67.7 \%$ & $14.3 \%$ & $28.3 \%$ & $89.8 \%$ & $6.0 \%$ \\
\hline
\end{tabular}

cannot be established, because the sulfur content of microalgae biomass was not measured and there is no direct inference on its ratio in biomass that can be drawn in a similar manner to that of nitrate and phosphate described above.

\section{Microalgae growth kinetic model}

The two non-linear mathematical models, Logistic and Gompertz models (Eqs. 7 and 8), were employed to fit and validate the growth period experimental data for the three species of microalgae under Cases 2 and 3, being the conditions where maximum growth was generally observed. These Logistic [6, 24] and Gompertz [24, 36] models are commonly used in illustrating rapid population growth of organisms:

$N(t)=\frac{N_{\max }}{1+\left(\frac{N_{\max }}{N_{0}}-1\right) \exp ^{-\mu t}}$

$N(t)=N_{0}\left(\exp \ln \left(N_{\max } / N_{0}\right)(1-\exp (-\mu t))\right)$

where $N$ is the biomass concentration $(\mathrm{mg} \mathrm{dw} / \mathrm{L}), t$ is the time for culture (day), $\mu$ designates apparent specific growth rate (/day), $N_{\text {max }}$ denotes the carrying capacity of microalgae limited by the environmental condition ( $\mathrm{mg} \mathrm{dw} / \mathrm{L})$, and $N_{0}$ is the initial biomass concentration ( $\mathrm{mg} \mathrm{dw} / \mathrm{L}$ ).

Figures 8, 9 show the results of the Logistic and Gompertz model fitting of the microalgae experimental growth data. The Gompertz model fits the microalgae growth curves better than the Logistic model at all growth conditions and microalgae species. In fact, the discrepancies between the experimental data and Logistic model for all microalgae species and growth conditions were extremely high. These values of coefficient of determination, $R^{2}$ and the adjusted $R^{2}$ (Table 4 ) further established the goodness of fit of the Gompertz model over the Logistic model in the study. The $R^{2}$ values greater than 0.90 (Table 4) indicated that the Gompertz model described more $90 \%$ variability of the microalgae biomass concentration. Moreso, the high values adj- $R^{2}$ for the Gompertz model (Table 4) imply that there was no overfitting, and that culturing time is a significant parameter for the microalgae growth profile. The specific growth rate ranged between 0.16 and 0.31 for $S$. obliquus, 0.25 and 0.30 for $O$. minuta, and 0.18 and 0.23 for C. vulgaris (Table 5).

\section{Lipid, carbohydrate, and protein content of microalgae}

The biochemical composition of microalgae biomass is largely dependent on the composition and concentration of growth nutrients available in culture medium [37]. Microalgae tend to accumulate more lipids or carbohydrate under the stressed conditions of nitrogen deficit [35, 39], $400 \mathrm{mM}$ salinity [40], high temperature of $38{ }^{\circ} \mathrm{C}$ [17], and high photoirradiation of $150 \mu \mathrm{mol} / \mathrm{m}^{2} \mathrm{~s}$ [37]. The harvested biomass under the different cases investigated was analyzed for their lipid, carbohydrate, and protein contents, and the results are presented in Fig. 10. In Fig. 10, the total percentage 
Fig. 8 Microalgae growth performance using Logistic and Gompertz models at Case 2: a

C. vulgaris, b S. obliquus, and c O. minuta
Fig. 9 Microalgae growth Gompertz models at Case 2: a C. vulgaris, b $S$. obliquus, and c O. minuta performance using Logistic and
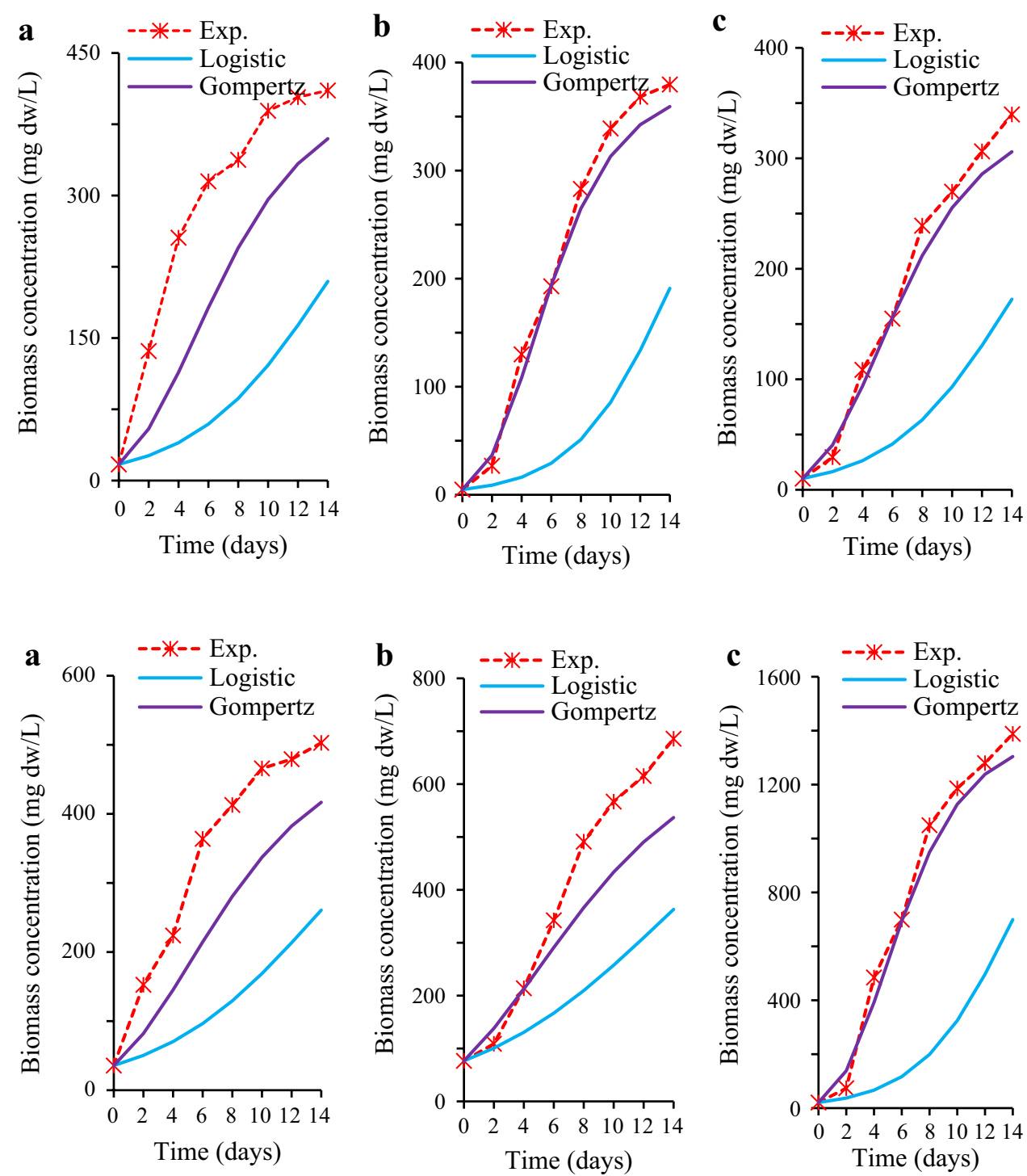

Table 4 Model evaluation by coefficient of determination, $R^{2}$, and adjusted $R^{2}$

\begin{tabular}{|c|c|c|c|c|c|c|c|c|}
\hline \multirow[t]{3}{*}{ Microalgae species } & \multicolumn{4}{|c|}{ Gompertz model } & \multicolumn{4}{|c|}{ Logistic model } \\
\hline & \multicolumn{2}{|l|}{$\overline{R^{2}}$} & \multicolumn{2}{|c|}{ Adjusted $R^{2}$} & \multicolumn{2}{|l|}{$R^{2}$} & \multicolumn{2}{|c|}{ Adjusted $R^{2}$} \\
\hline & Case 2 & Case 3 & Case 2 & Case 3 & Case 2 & Case 3 & Case 2 & Case 3 \\
\hline S. obliquus & 1.00 & 0.99 & 1.00 & 0.99 & 0.75 & 0.95 & 0.73 & 0.95 \\
\hline O. minuta & 0.99 & 0.99 & 0.99 & 0.99 & 0.87 & 0.76 & 0.86 & 0.74 \\
\hline C. vulgaris & 0.90 & 0.95 & 0.89 & 0.95 & 0.68 & 0.81 & 0.66 & 0.79 \\
\hline
\end{tabular}

composition of lipid, carbohydrate, and protein for each bar is less than 100, while all other cell components not analyzed account for the shortfall. A comparison of microalgae biomass lipid, carbohydrate, and protein contents has grown under different wastewater sources and other growth conditions reported by other authors, and the present study are shown in Table 6.
As shown in Fig. 10, there were no significant discrepancies in the lipid contents of the microalgae strains cultured under the different nitrate, phosphate, and sulfate concentrations of supplemented and not supplemented wastewater. The highest lipid contents of $11 \%, 13 \%$, and $17 \%$ were observed for $C$. vulgaris, S. obliquus, and $O$. minuta, respectively, under different cases of wastewater 
Table 5 Microalgae-specific growth rate, $\mu$ (/day) at different wastewater sample cases

\begin{tabular}{lllll}
\hline & \multicolumn{4}{l}{ Specific growth rate, $\mu$ (/day) } \\
\cline { 2 - 5 } & Case 1 & Case 2 & Case 3 & Case 4 \\
\hline S. obliquus & 0.20 & 0.31 & 0.16 & 0.17 \\
O. minuta & 0.23 & 0.25 & 0.30 & 0.25 \\
C. vulgaris & 0.22 & 0.23 & 0.19 & 0.18 \\
\hline
\end{tabular}

nutrients supplements studied. There was no significant difference between the minimum and maximum lipid contents recorded in all species and nutrient (sulfate, nitrate, and phosphate) studied. The maximum lipid contents obtained for $C$. vulgaris (11\%) and O. minuta (17\%) were obtained at high sulfate concentrations containing wastewater samples-Cases 4 and 3. In these cases, one may infer that the microalgae were under high sulfate stress, thus accumulate more lipids, though less significant. In the case of $S$. obliquus, the highest lipid content was observed at limiting nitrate and phosphate concentrations. These partial deviations of the present work from what is reported in the literatures might be a result of both nitrogen and phosphate being limiting nutrients (wastewater without nutrient supplements, Case 1) and high sulfate concentration (case 4) of the growth media used for the cultivations. Meanwhile, there are mixed reports on which of the biochemical components-lipid or carbohydrate is
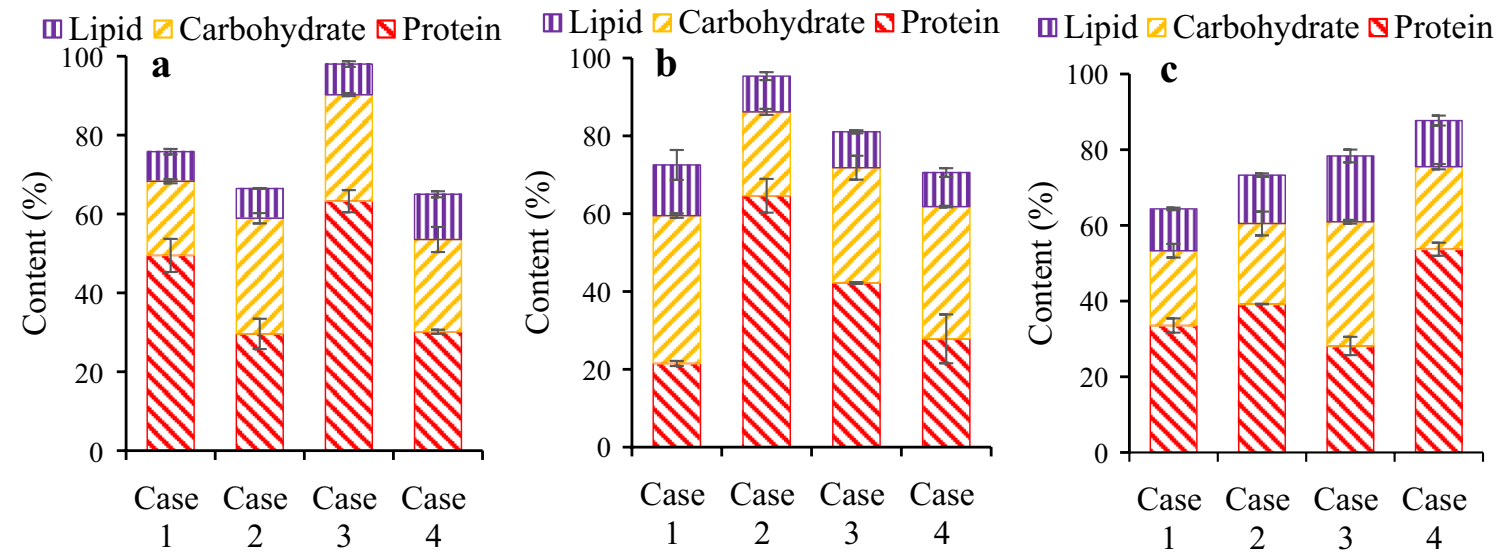

Fig. 10 The biochemical composition of microalgae species grown under different wastewater cases: a C. vulgaris, b $S$. obliquus, and c O. minuta

Table 6 A comparison of lipid, carbohydrate, and protein contents of microalgae strains in the present work with other authors

\begin{tabular}{|c|c|c|c|c|c|c|}
\hline \multirow[t]{2}{*}{ Media type } & \multirow[t]{2}{*}{ Microalgae type } & \multicolumn{3}{|c|}{ Biochemical content $(\%)$} & \multirow{2}{*}{$\begin{array}{l}\text { Culture } \\
\text { duration } \\
\text { (day) }\end{array}$} & \multirow[t]{2}{*}{ References } \\
\hline & & Lipid & Carbohydrate & Protein & & \\
\hline MSGW $^{\mathrm{a}}$ & C. vulgaris & 16.90 & 53.00 & 12.00 & 10 & [37] \\
\hline Aquaculture wastewater & S. obliquus & 30.85 & 35.05 & 19.52 & 14 & {$[28]$} \\
\hline BG 11 medium & S. obliquus & 20.30 & 19.70 & 44.40 & 16 & [6] \\
\hline Aquaculture wastewater & C. sorokiniana & 31.85 & 35.43 & 28.81 & 14 & [29] \\
\hline Wastewater & C. vulgaris & 9.81 & 16.84 & 35.13 & 30 & [41] \\
\hline Seawater & Scenedesmus sp. & 13.00 & 25.00 & 56.00 & - & [11] \\
\hline Municipal Wastewater & S. obliquus & 26.5 & 27.5 & 28.5 & 16 & {$[6]$} \\
\hline Artificial wastewater & Scenedesmus sp. & 12.8 & - & - & 15 & [42] \\
\hline Municipal wastewater ${ }^{\mathrm{b}}$ & O. minuta & 17.39 & 32.82 & 28.14 & 14 & This study \\
\hline Municipal wastewater ${ }^{\mathrm{c}}$ & S. obliquus & 13.04 & 38.00 & 21.5 & 14 & This study \\
\hline Municipal wastewater ${ }^{\mathrm{d}}$ & C. vulgaris & 11.47 & 23.39 & 30.14 & 14 & This study \\
\hline Municipal wastewater ${ }^{\mathrm{c}}$ & O. minuta & 11.06 & 19.77 & 33.55 & 14 & This study \\
\hline Municipal wastewater ${ }^{\mathrm{c}}$ & S. obliquus & 9.19 & 21.57 & 64.60 & 14 & This study \\
\hline Municipal wastewater ${ }^{\mathrm{e}}$ & C. vulgaris & 7.53 & 29.33 & 29.60 & 14 & This study \\
\hline
\end{tabular}

MSGW $^{\mathrm{a}}$ monosodium glutamate industrial wastewater, municipal wastewater ${ }^{\mathrm{b}}$ Case 3 , municipal wastewater ${ }^{\mathrm{c}}$ Case 1 , municipal wastewater ${ }^{\mathrm{d}}$ Case 4 , Municipal wastewater ${ }^{\mathrm{e}}$ Case 2 
more favored under any of the stress conditions. Pancha et al. [38] observed that under microalgae growth stressed condition of nitrate limitation, the biosynthesis of carbohydrate is more favored than lipid. Chokshi et al. [17] and Pancha et al. [40] observed that Acutodesmus dimorphus and Scenedesmus sp. accumulated more carbohydrate than lipid under nitrogen starved and temperature stress conditions, respectively. This is contrary to what is reported by $\mathrm{He}$ et al. [39] that nitrogen stress leads to more accumulation of lipid in C. vulgaris. Although the recorded values for lipid contents in the current study are lower compared to other authors, the values are still within the ranges reported, as depicted in Table 6.

Also, in Fig. 10, the carbohydrate contents of the microalgae strains under the different culture media show maximum values of $29 \%, 38 \%$, and $33 \%$ for $C$. vulgaris, $S$. obliquus, and O. minuta, respectively. There is a significant difference in the values obtained for carbohydrate and protein contents in the strains of microalgae under the different growth condition, unlike the lipid contents. The observed carbohydrate content of different microalgae strains is similar to what has been reported in the literatures, as shown in Table 6 . The values of carbohydrate reported in the biomass of $C$. vulgaris, S. obliquus, $C$. sorokiniana, and Scenedesmus sp. when cultivated under different wastewater sources were 17\% [41], 20\% [29], $35 \%$ [27], and 25\% [11], respectively. Meanwhile, a much higher value of carbohydrate content of about $53 \%$ was reported by Jiang et al. [37] when C. vulgaris was cultured in monosodium glutamate industrial wastewater.

In protein synthesis, nitrogen plays an important role, so decreasing its concentration or serially deleting it in microalgae growth medium resulted in reduction in the crude protein content of Scenedesmus sp. [38]. Figure 10b shows that protein content was highest (65\%) in S. obliquus when cultured in wastewater supplemented with certain level of sulfate, nitrate, and phosphate (Case 2). The maximum protein contents of $63 \%$ and $54 \%$ were observed in $C$. vulgaris and $O$. minuta when cultivated in wastewater supplemented with nutrients as Case 3 and Case 2, respectively. As shown in Table 6, the values obtained for protein content in the present study were not in deviance with the values reported by other authors. Ahmad et al. [6] report $44 \%$ protein content when S. obliquus cultured in BG 11 medium against $29 \%$ when the same species was cultivated in aquaculture wastewater. The authors attributed the lower value of protein observed in the aquaculture water to limiting nitrate compared to the BG 11 medium. The work by Jiang et al. [34] observed $12 \%$ protein content of $C$. vulgaris when grown in monosodium glutamate industrial wastewater, while Scenedesmus sp. contained 56\% protein when cultured in seawater.

\section{Conclusion}

This work has demonstrated the potential of $C$. vulgaris, $S$. obliquus, and $O$. minuta to grow in wastewater and sulfate-rich wastewater, with sulfate concentration higher than ranges of values reported for municipal wastewater sources $(<300 \mathrm{mg} / \mathrm{L},[10])$. The maximum biomass productivity of 33, 44, and $98 \mathrm{mg} \mathrm{dw} / \mathrm{L} / \mathrm{d}$ for C. vulgaris, S. obliquus, and $O$. minuta, respectively, was observed in wastewater sample Case 3 for microalgae strains evaluated. Also, the nutrient removal capacity of the three microalgae species revealed that nitrate and phosphate were taken up to a significantly greater extent compared to sulfate. The microalgae strain S. obliquus demonstrated the highest sulfate removal of $36 \%$, followed by $C$. vulgaris (35\%) and $O$. minuta with $27 \%$. The maximum nitrate removal was $93 \%, 86 \%$, and $69 \%$ for C. vulgaris, S. obliquus, and $O$. minuta, respectively. $O$. minuta showed a better phosphate uptake with more than $90 \%$ in all cases investigated. In all cases of wastewater employed as microalgae growth medium, carbohydrate (22-65\%), and protein (19-38\%) production were dominant over the lipid production $(8-17 \%)$, thus making the cultivated strains potential bioethanol candidates and protein source for animal feeds rather than biodiesel.

Although the present study does not include an economic analysis of microalgae application in wastewater, a detailed review and economic analysis of application of microalgae in wastewater treatment can be found in $[6,43,44]$. One of the major conclusions by researchers is that an integrated microalgae cultivation, wastewater treatment, and gas exhaust from industrial plants coupled with proper management of microalgae biomass into biofuels and co-products can be a worthwhile venture compared to current technologies.

Acknowledgements The authors acknowledged the supports of Frank H. Dotterweich College of Engineering, Wayne H. King Department of Chemical and Natural Gas Engineering, and College of Graduate Studies, Texas A\&M University-Kingsville, TX for doctoral scholarship and stipends.

\section{Compliance with ethical standards}

Conflict of interest The authors declare that they have no conflict of interest.

Open Access This article is licensed under a Creative Commons Attribution 4.0 International License, which permits use, sharing, adaptation, distribution and reproduction in any medium or format, as long as you give appropriate credit to the original author(s) and the source, provide a link to the Creative Commons licence, and indicate if changes were made. The images or other third party material in this article are included in the article's Creative Commons licence, unless indicated otherwise in a credit line to the material. If material is not included in the article's Creative Commons licence and your intended use is not permitted by statutory regulation or exceeds the permitted use, you will need to obtain permission directly from the copyright holder. To view a copy of this licence, visit http://creativecommons.org/licenses/by/4.0/. 


\section{References}

1. Fernández-linares, L.C., Barajas, C.G., Páramo, E.D., Corona, J.A.B.: Assessment of Chlorella vulgaris and indigenous microalgae biomass with treated wastewater as growth culture medium. Bioresour. Technol. 244, 400-406 (2017)

2. Sorokina, K.N., Yakovlev, V.A., Piligaev, A.V., Kukushkin, R.G., Kolchanov, N.A., Parmon, V.N.: Potential of microalgae as a source of bioenergy. Catal. Industry 4(3), 202-208 (2012)

3. Wang, L., Min, M., Li, Y., Chen, P., Chen, Y., Liu, Y., Wang, Y., Ruan, R.: Cultivation of green algae chlorella sp. in different wastewaters from municipal wastewater treatment plant. Appl. Biochem. Biotech. 162(4), 1174-1186 (2010)

4. Ashok, V., Shriwastav, A., Bose, P., Kumar, S.: Pycoremediation of wastewater using algal-bacterial photobioreactor: effect of nutrient load and light intensity. Bioresour. Technol. Rep. 7, 100205 (2019)

5. Piligaev, A.V., Sorokina, K.N., Shashkov, M.V., Parmon, V.N.: Screening and comparative metabolic profiling of high lipid content microalgae strains for application in wastewater treatment. Bioresour. Technol. 250, 538-547 (2018)

6. Ahmad, F., Ravindran, B., Kumar, S., Nasr, M., Rawat, I., Bux, F.: Techno-economic estimation of wastewater phycoremediation and environmental benefits using Scenedesmus obliquus microalgae. J. Environ. Manag. 240, 293-302 (2019)

7. Tibbetts, S.M., Whitney, C.G., MacPherson, M.J., Bhatti, S., Banskota, A.H., Stefanova, R., McGinn, P.J.: Biochemical characterization of microalgal biomass from freshwater species isolated in Alberta, Canada for animal feed applications. Algal Res. 11, 435-447 (2015)

8. Raslavi, L., Stri, N., Felneris, M.: New insights into algae factories of the future. Renew. Sus. Energy Reviews 81, 643-654 (2018)

9. Bowell, R.J.: A review of sulfate removal options for mine waters. Proc. Mine Water 2004, 75-91 (2004)

10. Zhou, H., Sheng, Y., Zhao, X., Gross, M., Wen, Z.: Treatment of acidic sulfate-containing wastewater using revolving algae bio fi $1 \mathrm{~m}$ reactors: sulfur removal performance and microbial community characterization. Bioresour. Technol. 264, 24-34 (2018)

11. Mohammadi, M., Mohammadi, M., Mowla, D., Esmaeilzadeh, F., Ghasemi, Y.: Cultivation of microalgae in a power plant wastewater for sulfate removal and biomass production: a batch study. J. Environ. Chem. Eng. 6, 2812-2820 (2018)

12. Pol, L.W.H., Lens, P.N., Stams, A.J., Lettinga, G.: Anaerobic treatment of sulphate-rich wastewaters. Biodegradation 9(3-4), 213-224 (1998)

13. Hautman, D.P., Munch, D.J.: Method 300.1 Determination of inorganic anions in drinking water by ion chromatography. In: US Environmental Protection Agency, Cincinnati, OH (1997)

14. Bligh, E.G., Dyer, W.J.: A rapid method of total lipid extraction and purification. Can. J. Biochem. Physiol. 37(8), 911-917 (1959)

15. Dubois, M., Gilles, K.A., Hamilton, J.K., Rebers, P.A., Smith, F.: Colorimetric method for determination of sugars and related substances. Anal. Chem. 28(3), 350-356 (1956)

16. Bradford, M.M.: A rapid and sensitive method for the quantitation microgram quantities of protein utilizing the principle of proteindye binding. Anal. Biochem. 254, 248-254 (1976)

17. Chokshi, K., Pancha, I., Trivedi, K., George, B., Maurya, R., Ghosh, A., Mishra, S.: Biofuel potential of the newly isolated microalgae Acutodesmus dimorphus under temperature induced oxidative stress conditions. Bioresour. Technol. 180, 162-171 (2015)

18. Mera, R., Torres, E., Abalde, J.: Effects of sodium sulfate on the freshwater microalga chlamydomonas moewusii: implications for the optimization of algal culture media. J. Phycol. 88, 75-88 (2016)

19. Lv, J., Guo, J., Feng, J., Liu, Q., Xie, S.: Effect of sulfate ions on growth and pollutants removal of self-flocculating microalga Chlorococcum sp. GD in synthetic municipal wastewater. Bioresour. Technol. 234, 289-296 (2017)

20. Shabman, L.A., Poff, J.A.: A Guide to the National Drinking Water Standards and Private Water Systems. In: Virginia Water Resources Research Center, Virginia Polytechnic Institute and State University; (1996)

21. Martin, C., De Noiie, J., Picard, G.: Intensive cultivation of freshwater microalgae on aerated pig manure. Biomass 7(4), 245-259 (1985)

22. Tucker, C.S., Abramo, L.R.D.: Managing high $\mathrm{pH}$ in freshwater ponds. In: Southern Regional Aquaculture Center (2008)

23. Park, J.B.K., Craggs, R.J., Shilton, A.N.: Wastewater treatment high rate algal ponds for biofuel production. Bioresour. Technol. 102(1), 35-42 (2011)

24. Lam, M.K., Yusoff, M.I., Uemura, Y., Lim, J.W., Khoo, C.G., Lee, K.T., Ong, H.C.: Cultivation of Chlorella vulgaris using nutrients source from domestic wastewater for biodiesel production: growth condition and kinetic studies. Renew. Energy 103, 197-207 (2017)

25. Mohammadi, M., Mowla, D., Esmaeilzadeh, F., Ghasemi, Y.: Enhancement of sulfate removal from the power plant wastewater using cultivation of indigenous microalgae: stage-wise operation. J. Environ. Chem. Eng. 7(1), 102870 (2019)

26. Yadav, K.K., Gupta, N., Kumar, A., Reece, L.M., Singh, N., Rezania, S., Khan, S.A.: Mechanistic understanding and holistic approach of phytoremediation: a review on application and future prospects. Ecol. Eng. 120, 274-298 (2018)

27. Znad, H., Al Ketife, A.M.D., Judd, S., Almomani, F., Vuthaluru, H.B.: Bioremediation and nutrient removal from wastewater by Chlorella vulgaris. Ecol. Eng. 110, 1-7 (2018)

28. Zhou, W., Li, Y., Min, M., Hu, B., Zhang, H., Ma, X., Li, L., Cheng, Y., Chen, P., Ruan, R.: Growing wastewater-born microalga Auxenochlorella protothecoides UMN280 on concentrated municipal wastewater for simultaneous nutrient removal and energy feedstock production. Appl. Energy 98, 433-440 (2012)

29. Ansari, F.A., Singh, P., Guldhe, A., Bux, F.: Microalgal cultivation using aquaculture wastewater: integrated biomass generation and nutrient remediation. Algal 21, 169-177 (2017)

30. Kiran, P., Krishna, S.V., Verma, K., Pooja, K., Bhagawan, D., Himabindu, V.: Phycoremediation of sewage wastewater and industrial flue gases for biomass generation from microalgae. S. Afr. J. Chem. Eng. 25, 133-146 (2018)

31. Guldhe, A., Ansari, F.A., Singh, P., Bux, F.: Heterotrophic cultivation of microalgae using aquaculture wastewater: a biorefinery concept for biomass production and nutrient remediation. Ecol. Eng. 99, 47-53 (2017)

32. Kim, G., Mujtaba, G., Lee, K.: Effects of nitrogen sources on cell growth and biochemical composition of marine chlorophyte Tetraselmis sp. for lipid production. Algae 31(3), 257-266 (2016)

33. Cai, T., Park, S.Y., Li, Y.: Nutrient recovery from wastewater streams by microalgae: status and prospects. Renew. Sust. Energ. Rev. 19, 360-369 (2013)

34. Halip, A.A., Yaakob, Z., Rozaimah, A.S.: Analysis of the elemental composition and uptake mechanism of Chlorella sorokiniana for nutrient removal in agricultural wastewater under optimized response surface methodology (RSM) conditions. J. Clean. Prod. 210, 673-686 (2019)

35. Voltolina, D., Cordero, B., Nieves, M., Soto, L.P.: Growth of Scenedesmus sp. in artificial wastewater. Bioresour. Technol. 68(3), 265-268 (1999)

36. Jukić, D., Kralik, G., Scitovski, R.: Least-squares fitting Gompertz curve. J. Comput. Appl. Math. 169(2), 359-375 (2004) 
37. Jiang, L., Ji, Y., Hu, W., Pei, H., Nie, C., Ma, G., Song, M.: Adjusting irradiance to enhance growth and lipid production of Chlorella vulgaris cultivated with monosodium glutamate wastewater. J. Photochem. Photobio. B Biol. 162, 619-624 (2016)

38. Pancha, I., Chokshi, K., George, B., Ghosh, T., Paliwal, C., Maurya, R., Mishra, S.: Nitrogen stress triggered biochemical and morphological changes in the microalgae Scenedesmus sp. CCNM 1077. Bioresour. Technol. 156, 146-154 (2014)

39. He, P.J., Mao, B., Shen, C.M., Shao, L.M., Lee, D.J., Chang, J.S.: Cultivation of Chlorella vulgaris on wastewater containing high levels of ammonia for biodiesel production. Bioresour. Technol. 129, 177-181 (2013)

40. Pancha, I., Chokshi, K., Maurya, R., Trivedi, K.: Salinity induced oxidative stress enhanced biofuel production potential of microalgae Scenedesmus sp. CCNM 1077. Bioresour. Technol. 189, 341-348 (2015)

41. Zhao, B., Ma, J., Zhao, Q., Laurens, L., Jarvis, E., Chen, S., Frear, C.: Efficient anaerobic digestion of whole microalgae and lipid-extracted microalgae residues for methane energy production. Bioresour. Technol. 161, 423-430 (2014)

42. Cordero, B., Nievesc, M., Sotoc, L.P.: Growth of Scenedesmus in artificial wastewater. Bioresour. Technol. 68(3), 265-268 (1998)

43. Singh, V., Tiwari, A., Das, M.: Phyco-remediation of industrial wastewater and flue gases with algal-diesel engenderment from micro-algae: a review. Fuel 173, 90-97 (2016)

44. Gouveia, L., Graça, S., Sousa, C., Ambrosano, L., Ribeiro, B., Botrel, E.P., Neto, P.C., Ferreira, A.F., Silva, C.M.: Microalgae biomass production using wastewater: treatment and costs: scaleup considerations. Algal Res. 16, 167-176 (2016)

Publisher's Note Springer Nature remains neutral with regard to jurisdictional claims in published maps and institutional affiliations. 